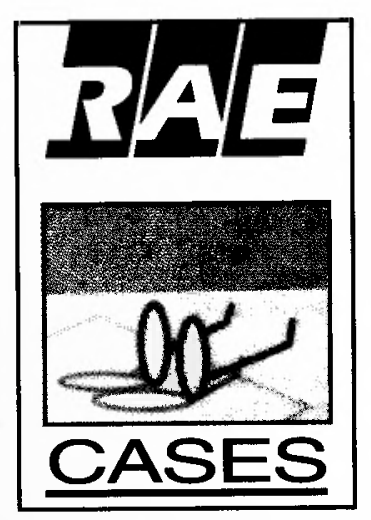

\title{
DESAFIO DA QUALIDADE E OS IMPACTOS DAS TRANSFORMAÇÕES EM ORGANIZAÇÕES BAIANAS
}

\section{Reflexão acerca das potencialidades e dos limites de novos métodos} de gestão.

Reflection on potentialities and limits of new management methods.

PALAVRAS-CHAVE:

Qualidade, organizações, retórica, cultura.

\section{KEY WORDS:}

Quality, organizations, rhetoric, culture.
*Professora Titular e Coordenadora do Núcleo de PósGraduação em Administração (NPGA) da UFBA.

**Professora Bolsista do NPGA UFBA.

*** Coordenadora de Cursos de Pós-Graduação do NPGA/ UFBA.
O final do século trouxe novas tecnologias, novos padrões e novas expectativas, em meio à recessão e ao desemprego, à economia global e ao localismo, mas principalmente novas palavras no universo de comunicação organizacional. "Diga feira e você pensa em energia, surpresa, movimento, alegria"1.

Se a penúltima metáfora é a organização virtual ${ }^{2}$, ação e excelência são imperativos da prática empresarial. Lembrando a circularidade observada por Gumesson ${ }^{3}$ quanto à prática e à teoria no estudo de organizações, ambas impuseram-se como objetos de pesquisa na análise da vertiginosa dinâmica empresarial dos anos 90 , ou seja, da ação de consultores à reflexão acadêmica e vice-versa.

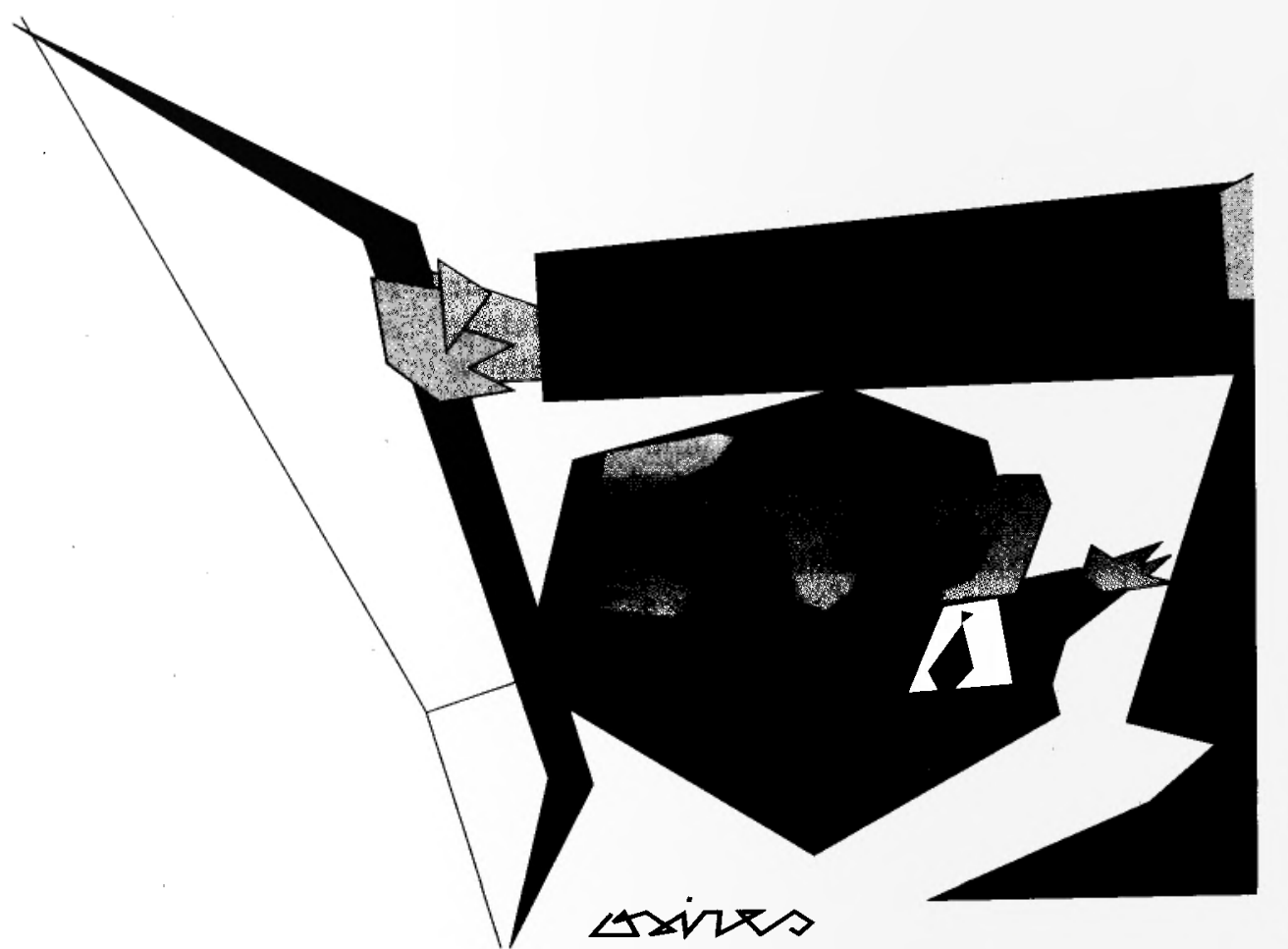

São Paulo, v. 35, n. 1, p. 56-69 
A questão que se coloca é o quanto as palavras de ordem da retórica não tão nova, mas certamente reciclada da ação e, principalmente, da excelência, integram não só o discurso, mas também a prática das organizações, de forma a impactar nas chamadas culturas organizacionais.

Por que avaliar o impacto nas culturas?

A resposta a essa questão pode ser a grande importância que os projetos de mudança organizacional dão à cultura; que é ora confundida com a própria organização, ora distinguida de outros componentes como a dimensão sócio-estrutural ou a ação dos atores ${ }^{4 .}$

Especialmente os projetos da qualidade total têm a pretensão de mudar a cultura, conforme pregam não só Deming, Juran e Crosby como os difusores da qualidade total no Terceiro Mundo. Qualidade é símbolo do mérito organizacional ${ }^{5}$.

Os pacotes de consultoria disseminados no Brasil pelos chamados nucleadores do Programa Brasileiro de Qualidade e Produtividade incorporaram a retórica da excelência e a difundiram. As grandes e pequenas consultoras copiaram esses pacotes e os disseminaram, com bons e maus resultados que a banalização de um conceito implica.

Não há dúvida que, no caso brasileiro, qualidade tem hoje um significado na sociedade, especialmente nas organizações competitivas. A mídia gerencial tem se incumbido de difundir conceitos e práticas até em veículos de grande circulação como a Folha de S. Paulo. O ideário da qualidade é traduzido para o consumo massivo.

Há um grande cuidado em se manter simples e simplificar mais os conceitos, mesmo que as concepções de qualidade tenham evoluído da inspeção e controle para o aperfeiçoamento e a gestão estratégica. A retórica da excelência foi sendo enriquecida com novas expressões que designam ações cada vez mais complexas e ambiciosas, onde se espera que a organização se transforme em vários níveis, da cúpula dirigente ao chão da fábrica, da estratégia às práticas cotidianas.

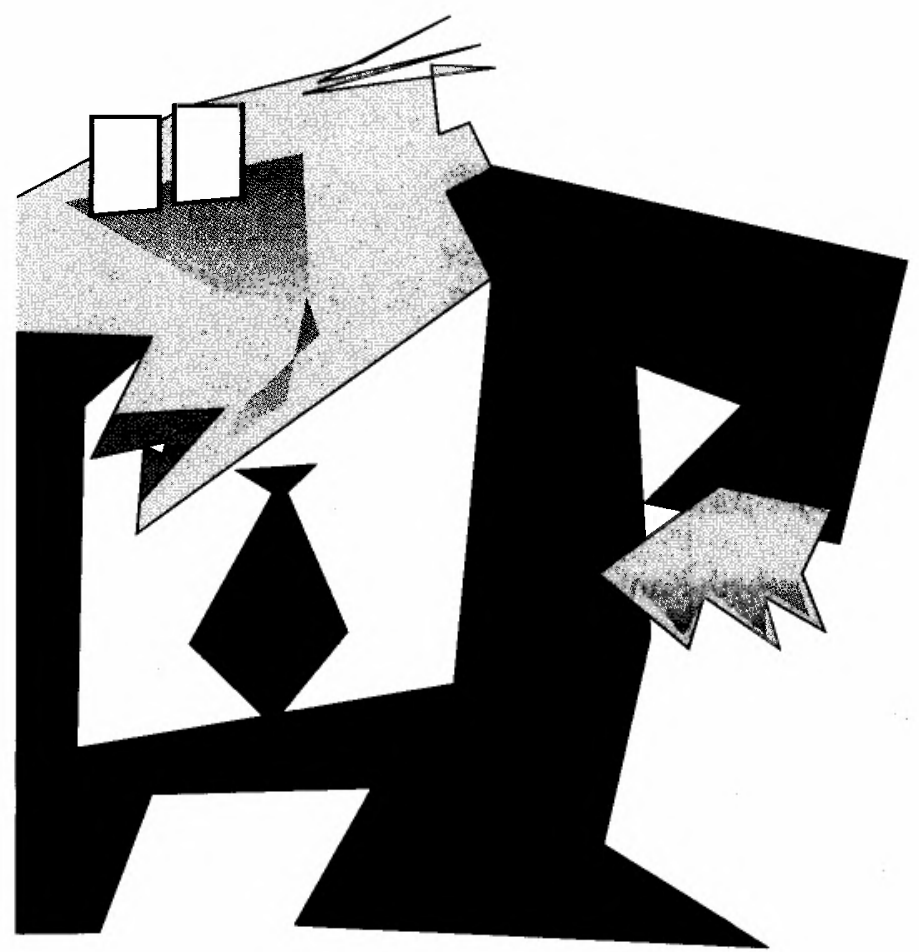

(C) 1995, Revista de Administração de Empresas / EAESP / FGV, São Paulo, Brasil.
1. PETERS, T. Rompendo as barreiras de Administração. Harbra: São Paulo, 1993.

2. ETTIGHOFER, D. L'entreprise virtuelle. Paris: Odil Jacob, 1992.

3. GUMESSON, E. Qualitative methods in management research. London: Saje, 1992.

4. ABRANAVEL, H. et al. Cuentura organizacional. México: Fundo Empresarial Legis, 1992.

5. BROOKE, C. Simbols and shambles. Quality and Organizational Change. Anais do International Standing Conference of Organizational Symbolism. Barcelona, 1993. 
Entre os temas pesquisados ${ }^{6}$, elegemos como temática os processos socioculturais derivados da adoção de Programas de Qualidade em duas organizações baianas - a Alfa e a Beta, nomes fictícios. Esses processos serão analisados sob a perspectiva da retórica utilizada pelo pessoal envolvido, ao se avaliarem as transformações dessas organizações, identificadas como transformações na cultura empresarial.

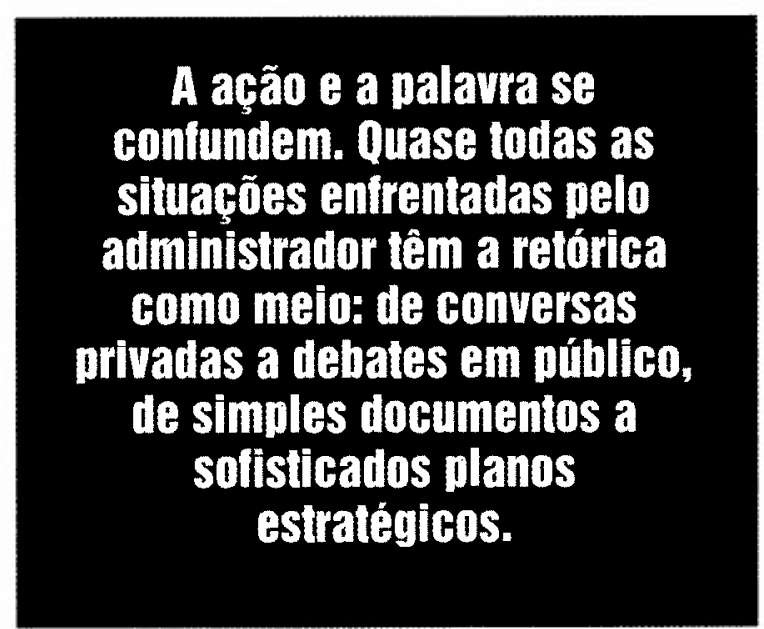

\section{A RETÓRICA DA EXCELÊNCIA}

A definição mais simples da retórica é eloqüência ${ }^{7}$. Eloqüência supõe ênfase na comunicação, discurso convincente e persuasão.

Retórica é também o campo formal de estudo que usa a linguagem para condicionar o agir e o pensar humanos. O condicionamento do pensamento e da ação, por sua vez, é o alvo preferencial da atividade gerencial.

Quando Chanlat e Bedard ${ }^{8}$ consideram a gestão como um affaire de parole, referem-se aos estudos clássicos de Mintzberg, que associam a função do executivo como desempenho e interações verbais. Se alguns achados de Mintzberg, datados de quase 20 anos, foram

6. Este trabalho é subproduto da pesquisa Tecnologias de Gestão Avançada em Qualidade: estudos de casos de organizacões baianas, que vem sendo desenvolvida no NPGAUJFBA - Núcleo de Pós-Graduação em Administração, da Universidade Federal da Bahia. A pesquisa integra um consórcio formado por dez organizações baianas que implantaram Programas de Qualidade, cujos interesses atuais voltamse para estudos de tópicos relacionados à gestão empresarial avançada.

7. Holanda Ferreira, A. B. Novo dicionário da língua portugue sa. RJ: Nova Fronteira, 2.ed., 1986.

8. CHANLAT, A, BEDARD, R. Gestion: un affaire de parole. L'individu dans l'organisation. Québec: Éditions Eska, 1991.

9. LEMAîTRE, P. Controverse: à propos de recherche d'Henry Nitgberg sur le travail de manager. Revue Française de Gestion, n. 97, Paris, 1994.

10. JOHNSON, R. Leadership for the quality transformation. Quality Progress, EUA, Jan. 1993; CONGER, J. The charismatic leader. Londres: Jossey Bass, 1990.

11. ECLES, R., NORIA, N. Beyond the hipe. Boston: Harvard Business School Press, 1992. contestados (como o foram por Lemaître ${ }^{9}$ ), o mesmo não ocorreu, até então, quanto a aspectos metodológicos e conceituais mais genéricos, particularmente no que se refere ao uso da linguagem como meio privilegiado de ação.

Nesse sentido a ação e a palavra se confundem. Quase todas as situações enfrentadas pelo administrador têm a retórica como meio: de conversas privadas a debates em público, de simples documentos a sofisticados planos estratégicos.

A retórica é uma construção individual que só se atualiza no plano social. Traduz uma forma especial de ver o mundo e é o recurso do "líder visionário", hoje mais do que nunca associado às transformações organizacionais ${ }^{10}$.

Eccles e Nohria ${ }^{11}$ associam vigor à retórica como condição necessária.

Uma retórica vigorosa, plena de energia, é capaz de persuadir e fazer as coisas acontecerem. Indispensável, portanto, ao agir administrativo, ao (ad)ministrar.

Como lembram esses autores, "a maneira pela qual as pessoas falam do mundo está relacionada com a maneira pela qual o mundo é compreendido e, em última análise, com a maneira pela qual essas pessoas atuam nele, e o conceito de mudança revolucionária depende em grande parte da maneira pela qual o mundo é estruturado pela linguagem".

Os gurus da mudança, como Tom Peters e Rossbeth Kanter, são campeões da retórica bem como da excelência. Juran, Crosby, Ishikawa, Deming e Tagwchí, que, no Brasil, têm discípulos como Falconi, têm discurso claro, estruturado, simples e persuasivo. Como líderes sociais têm "visões do futuro" - que será melhor que o presente —, havendo uma tensão criativa entre a realidade e a "terra prometida", o que facilita a aceitação dos discursos da transformação.

Como ocorre esse processo e que reais impactos tem na chamada cultura empresarial é o que se verá a seguir, não sem antes se discutir o conceito da cultura em contraponto com o ideário da qualidade. 


\section{O IDEÁRIO DA QUALIDADE E 0 APORTE dOS ESTUDOS SOBRE CULTURA E ORGANIZAÇÕES}

Ao propor processos de transformação à organização como um todo, o ideário da qualidade apóia-se em alguns princípios:

- a totalidade, a globalidade;

- a visão holística da organização;

- a coletividade, o engajamento;

- a parceria, a participação, a solidariedade;

- a motivação, a criatividade;

- a comunicação;

- a liderança, o gerenciamento;

- o controle apropriado.

Há algumas diferenças de enfoque da gestão da qualidade na corrente que Giroux e Landry ${ }^{12}$ chamam de técnico-gerencial; a abordagem sistemática usada por Ishikawa, Taguchi e Ohoko prevê a análise minuciosa e o melhoramento progressivo e concreto dos processos de produção. A gestão ou o desempenho é um dado, conseqüência de uma implantação bem-sucedida implantação.

A segunda, chamada sistemista, tendo Deming e Juran como principais líderes americanos, valoriza a mudança de visão, de filosofia, da parte dos dirigentes e empregados, sendo o uso do ferramental, secundariamente, facilitado pela mudança provocada pela qualidade total. Especialmente nessa corrente, cultura é um conceito-chave. A gestão da qualidade total tem a mudança da cultura como alvo.

A filosofia gerencial da qualidade deposita, nesse conjunto de valores, papéis e atitudes, uma dimensão-chave no planejamento, controle e aperfeiçoamento do resultado. E é nesse sentido que têm sido desenvolvidas abordagens alternativas para a gestão de organizações as mais variadas possiveis, as quais, todavia, partem de uma premissa básica: todas as organizações têm uma cultura, que pode ser ou não eficiente e bem-sucedida.

Entretanto, a literatura da qualidade não aprofunda suficientemente o tema cultura, apesar de indicar que as empresas, no futuro, irão competir com maior sucesso se criarem um sistema de valores, crenças e comportamentos (individuais e de equipe) - uma cultura, portanto, necessária para esse sucesso ${ }^{13}$.

Os exemplos americanos e japoneses ilustram a importância de se compreender as determinações ambientais e culturais particulares e exclusivas, que deveriam balizar a adoção de estratégias gerenciais de qualidade.

Nos EUA, as práticas baseiam-se mais nas tradições e na cultura americana, que dão grande valor à liberdade de escolha do indivíduo, particularmente em sua participação nas diversas atividades: portanto, os propósitos de cooperação, lealdade etc. não podem ser impostos pelo groupism. No Japão, ao contrário, a cultura valoriza a conformidade, a hierarquia da autoridade: os trabalhadores japoneses fazem aquilo que a sociedade e a organização esperam que eles façam e há um grande receio do fracasso e da resultante perda de prestígio ${ }^{14}$.

Entretanto, alguns autores da Qualidade tratam a cultura como uma variável que pode ser gerenciada ou modificada desde que determinadas prescrições sejam seguidas. Schein, Pettigrew, Weick, Abranavel, Ouchi, Shrivaste, Miller, Johnson ${ }^{15}$ têm em comum a crença de que a cultura é gerenciável e transformável segundo o que se deseja.

Ao se tratar a cultura como variável dependente, que pode ser
12. GIROUX, $H$., LANDRY, $S$. Qualité Totale. Gestion, École des Hautes Études Commerciales de Montréal, v. 18, n. 4, nov. 1993.

13. JURAN, J. Controle da Qualidade. São Paulo: Makron Books. 1991.

14. Idem, ibidem.

15. SCHEIN E. La cultura empresarial y el liderrazzo. Madri: Plaza e James, 1988; PETTIGREW, 0. The management of strategia change. Oxford: Basil Blackwele, 1987; WEICK, H.K. Organizational culture as source of high realiability. California Management Review, v. XXIX, n.2, 1987, ABRANAVEL, $H$. Op. cit.; OUCHI, W., TEORIEZ, Z. Como as empresas podem enfrentar o desafio japonês. São Paulo: Fundo Educativo, 1982; SHRIVASTA, P. Integrating strategy formulation with organizational culture. The Journal of Business Strategy, v.5, 1985; MILLER, L. M. American spirit: visions of a new corporate culture. New York: William Morrow, 1984 
diagnosticada, gerenciada, manipulada e transformada por líderes "que têm visão" e gerentes que têm carta branca para promover mudanças predefinidas em profundidade e extensão, acredita-se ser possível evoluir de um estágio para outro: de uma cultura perdedora para outra, ganhadora ou vitoriosa.

$\mathrm{Na}$ retórica da excelência, não há lugar para

Assim, idélas, valores, atiludes e modos de comportamento próprios de certas organizações resultam da Interaģão entre diversas signilicącões individuais (inclusive seus lideres), da interąão entre difierenciadas subeulturas representadas pelos individuos. os perdedores, para os que criam ou são afetados por conflitos, para os que têm emoções negativas, ansiedades, inveja ou stress.

Os problemas da implantação não existirão se houver uma estratégia motivacional eficiente $^{16}$. A implantação é considerada variável dependente e a motivação pode ser assegurada por treinamento e estímulos.

Este é o ponto de ingresso para a chamada "mudança cultural", que, na prática, é mudança comportamental. Confunde-se cultura com comportamentos de atores, com práticas, com posturas, dentro de uma ótica simplista de determinismo cultural.

No entanto, o uso abusivo do termo cultura para significar tanto comportamentos, como práticas e crenças, e ainda, a totalidade organizacional, tem sido contestado ${ }^{17}$. Schneider ${ }^{18}$ chama cultura de lata de lixo, onde tudo cabe e tudo pode ter significado.

Aktouf ${ }^{19}$ não trata com menos rigor: "A primeira vista tem-se a impressão de que se trata de um quarto de despejo onde lideranças, valores, simbolos, mitos, lendas, sagas, anedotas, crenças, estruturas, hábitos, linguagem, ritos, cerimônias, regras sociais, normas, credos, filosofias de gestão, saber compartilhado, maneira de ser e vestir, determinantes inconscientes etc. se entrecruzam $e$ colidem desordenadamente." O próprio autor conclui que, qualquer que seja a escola na corrente dominante, a "cultura da empresa é a mágica comunhão de todos, patrões e operários, dirigentes e dirigidos, em um mesmo e entusiástico movimento de sustentação da empresa e de seus dirigentes."

Schein ${ }^{20}$ sugere que um dos papéis-chave da administração é saber quando as contribuições individuais e de equipe serão necessárias para criar formas e sistemas de compensação que produzirão as normas apropriadas de comportamento ${ }^{21}$.

Para Miller ${ }^{22}$, a administração precisa definir e criar a cultura necessária à otimização do desempenho da empresa; a obtenção da cultura desejada pede planejamento. $O$ autor identificou oito valores principais que promovem a lealdade do empregado, a produtividade e a inovação em empresas americanas. São eles: propósito, consenso, excelência, unidade, desempenho, empirismo, intimidade, integridade. Entretanto, o próprio Miller ${ }^{23}$ e outros autores, como Sethi, Namiki e Swanson ${ }^{24}$, advertem que as organizações empresariais do Ocidente não podem atender às exigências futuras copiando as técnicas das companhias que são sucesso atualmente, sejam elas japonesas ou americanas.

As mudanças comportamentais requeridas pela filosofia gerencial da qualidade dependem fortemente da capacidade da liderança em interpretar os condicionantes culturais presentes na organização (e que são exclusivos). A ênfase na mudança total (e cega), por vezes, destrói antigas tradições, rituais e comportamentos que talvez fossem elementos fundamentais e caros à organização, sem os quais se perde a identidade. A crença de que a cultura é gerenciável e transformável segundo o que se deseja, a nosso ver, traduz uma idéia simplista de "cultura" de modo que pode induzir a sérios equívocos na condução de processos, como alerta Cormack ${ }^{25}$. 
Nesse sentido, as organizações não são "apenas" o resultado de um sistema de regras e de atividades racionalmente ordenadas, nem tampouco apenas produto das relações de interdependência ambiental externa (ainda que essas características sejam de extrema rclevância para a análise organizacional). As abordagens atuais nesse campo têm, conseqüentemente, valorizado (cabe-nos dizer, a partir das mais variadas matrizes teórico-metodológicas), a interpretação da cultura da organização, chegando mesmo, no caso de determinadas correntes, a afirmar que "as organizaçôes são culturas" 26 .

Desse modo, a especificidade torna-se elemento importante na análise dos processos organizacionais: o que faz sentido para uma organização é, por vezes, completamente estranho para outra - as organizações têm identidade, passado, presente e, talvez, futuro ${ }^{27}$.

De pronto, devemos afirmar que, cientes da diversidade de posturas c interpretações, compartilhamos com a noção de que "o verdadeiro lugar da cultura são as interaçóes individuais e, no plano subjetivo, é o mundo de significações que cada um pode construir para si, por meio de suas relaçōes com outrem ${ }^{\prime \prime 28}$.

Assim, idéias, valores, atitudes e modos de comportamento próprios de certas organizações resultam da interação entre diversas significações individuais (inclusive seus líderes), da interação entre diferenciadas subculturas representadas pelos indivíduos.

Esse amálgama de subculturas ć que tece a cultura da organização e The confere a especialidade, até porque "o grau de conformidade entre a conduta social de um dado individuo e a cultura típica ou coletiva de um grupo vuria enormemente" 29 .

No âmbito organizacional, o surgimento e a consolidação de um sistema de valores resultam, segundo Gagliardi ${ }^{30}$, da complexidade e distribuição diferenciada de informaçoese e poder dentro da estrutura. Nessa perspectiva, os valores influenciam na delimitação do desenho organizacional, ao indicarem, por exemplo, operações e arranjos prioritariamente observados, além de formarem a imagem transmitida ao contexto externo, sobre o que se pode esperar da organização.

Os componentes funcionais e os componentes simbólicos de uma organização integram-se em combinações múltiplas e díspares ${ }^{31}$. As organizações combinam lógica e ação, o "pensar fazendo", c a retórica é usada como recurso privilegiado na construção do paradigma cultural.

A retórica da excelência na vertente técnico-gerencial, quer sistemista, pretende construir "organizações qualificadas" 32 .

De nossa amostra de dez organizações baianas, selecionamos duas empresas industriais de grande porte, consideradas bem-sucedidas na implantação de programas de qualidade.

A forma diferenciada como a retórica da excelência impacta nos níveis gerenciais e operacionais pode ser identificada nos discursos de dirigentes e "peões". A retórica da excelência, como se verá, é "desconstruída" e reconstruída segundo o nível de poder de cada depoente.

\section{ADOCÃO DO PROGRBMA DE OUALUATE GM CMLPESAS IAMARS}

\section{Beta S.A}

A Beta S.Aé uma empresa metalúrgica de capital e tecnologia intensivos. O seu faturamento chega a US\$100 milhões/ano. É a segunda importadora do Brasil; a primeira é a Petrobrás. Possui
26. SMIRCICH, L. Concepts of culture and organizational analysis. Administrative Science Quarterly, v. 28, n. 3, 1983, p. 339-58,

27. FISCHER, T., FRANÇA, G. Op. cit.

28. SAPIR, E. Cultura e personalidade. Anthropologie. Paris: Ed. de Minuit, 1967.

29. Idem, ibidem.

30. GAGLIARDI, P. The creation and change of organizational cultures: a conceptual framework. Organization Studies, v. 7 , ก. 2,1986, p.117-34.

31.TURNER, B.Connoisse urship in the study of organizational cultures. Doing research in organizations. Londres: Rontledges, 1988

32. GAGLIARDI, P. Op. cit. 
1.300 empregados diretos e 1.000 indiretos, com salário médio de US $\$ 800$. Produz cobre metálico, cerca de 160 mil toneladas/ano; no ano de 1992 exportou 90 mil toneladas. É a única metalúrgica de cobre no Brasil e a mais recente no mundo. Utiliza tecnologia de ponta, sendo considerada a mais moderna do mundo neste setor.

Após a privatização, em setembro de 1988, a Beta procedeu ao realinhamento no tipo de gestão e passou a usar a qualidade total, no estilo japonês, sendo o programa monitorado.

Para solucionar os problemas encontrados após a privatização, algumas medidas iniciais foram tomadas, e todas elas basearamse no princípio de que o produto deveria ser melhorado, o preço deveria alcançar níveis que a concorrência pudesse suportar e os custos da produção deveriam diminuir, sem que se colocasse em risco a qualidade do produto. Para isso, a Beta adotou os seguintes programas:

- expansão da produção para o máximo que as instalações pudessem suportar (se necessário, far-se-iam investimentos marginais);

- estabelecimento de paridade internacional dos preços;

- redução de custos;

- gestão com qualidade total;

- elaboração de plano trienal com metas claras.

O destaque da Beta foi para a capacitação dos seus empregados. Para a implementação das mudanças foram enviados técnicos a diversas empresas, inclusive de outros países, para que se observassem as di-

A filosolia gerencial da qualidade deposita, neste conjunto de valores, papéis e atitudes, uma dimensão-chave no planejamento, controle e aperfeiçoamento do resultado. E é neste sentido que têm sido desenvolvidas ahordagens altemativas para a gestâo de organizações. ferenças existentes na parte tecnológica e de gestão. Houve também a identificação $e$ participação em fóruns, buscando-se o aprimoramento do saber na tecnologia de cobre. Foram formadas e capacitadas pessoas para a transmissão dos conhecimentos.

Neste setor de capacitação de recursos humanos a empresa gasta, anualmente, US\$ 9 milhöes, o que corresponde a $2 \%$ do ativo anual.

Como resultado da auditoria operacional houve ainda uma redução do estoque em $60 \%$ dos itens.

Concepção e gerência do processo de melhoria da qualidade

A concepção defendida baseou-se num ambiente competitivo porque fora perdido o domínio sobre o preço e o lucro passara a ser mera conseqüência. Na visão japonesa, adotada pela Beta, o preco é decidido pelo mercado e.o lucro, pelo investidor. Outro princípio defendido refere-se ao objetivo das organizaçōes humanas que, estando claro, torna possível alinhar o trabalho de um grupo de pessoas para um mesmo alvo. As pessoas organizam-se para garantir a sobrevivência. No caso da empresa é a sobrevivência no mercado internacional. 
Baseando-se no TQC (Total Quality Control), a Beta adota o conceito de qualidade, atribuindo-lhe a seguinte característica: quem produz o produto não the atribui qualidade, este é um atributo dado por quem adquire o produto; se quem adquire o produto é o cliente, há que se buscar informações sobre quais são as suas necessidades.

Para a Beta, o cliente precisa de custo, atendimento em tempo hábil e principalmente segurança. No entendimento da empresa, os clientes são:

os consumidores, que buscam qualidade, preço, custo, atendimento;

os empregados, que querem remuneração, condições de trabalho e crescimento humano;

os acionistas, que precisam ter lucro, retorno do investimento; a sociedade, cujo interesse está voltado ao meio ambiente, impostos e outros benefícios.

Onde e em quê se concentrou o problema da empresa? A Beta considera que o problema da empresa é a diferença entre o que ela consegue oferecer aos clientes, em termos de custo, atendimento, ambiente moral, segurança, e o que o "melhor do mun$\mathrm{do}^{\prime \prime}$ - o concorrente - consegue fazer. Quando se fala de problemas, fala-se de resultado indesejável e também de formas de gerenciar e resolver os problemas. Na gestão dos problemas a empresa está consciente de que é preciso quantificar as causas e os efeitos para serem gerenciados.

A Beta entende que a sua gestão bascia-se na utilização de conceitos claros e métodos simples. Os problemas identificados passam a ser objeto de resolução, utilizando-se o Método de Análise e Solução de Problemas - MASP. Na análise do problema, busca-se utilizar uma visão muito clara de causa e efeito. $O$ efeito é o resultado desejado e a causa é a matéria-prima, método de trabalho e mão-de-obra.

Tendo a análise de Pareto como ferramenta, a Beta busca identificar as causas e, numa visão concentrada, a realidade do problema. Cuida para não tratar da causa errada ou, simplesmente, resolver aquele problema que aparece, que impressiona mais; a falta de dados pode levar com freqüência ao tratamento de causas que são menos importantes, porque são as mais fáceis.

A Beta vale-se do diagnóstico e do planejamento para ter as indicações do que vai ser feito, como, por quê, quando, por quem c qual é o melhor método a ser adotado para a solução; as pessoas são trcinadas para executar o planejamento, para exccutar a tarefa segundo o que o diagnóstico determina.

\section{Repercussões do processo e impactos na cultura da organização}

A Beta preconiza que o que mudou fundamentalmente na $\mathrm{em}-$ presa foi a filosofia gerencial. Adotam-se hoje, como princípios fundamentais, quatro pontos:

a satisfação dos clientes, o cuidado com o produto;

a referência aos padrōes de desempenho do concorrente; 


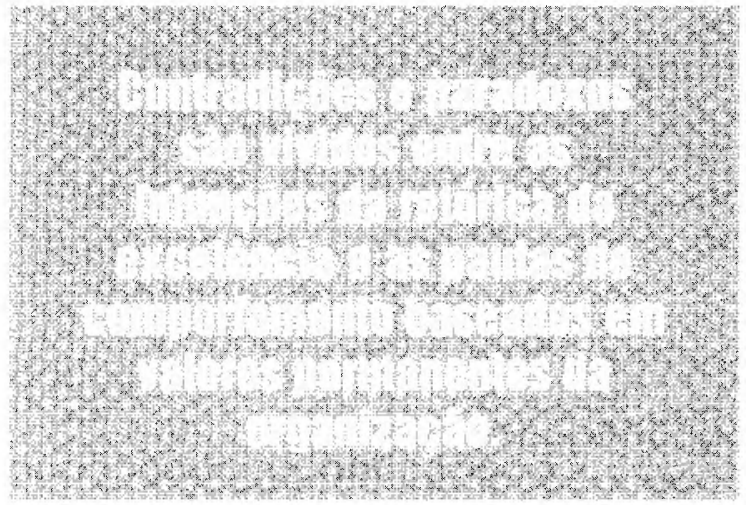

a resolução participativa dos problemas;

a melhoria contínua dos processos e métodos de trabalho.

A empresa entende que, se antes os problemas e as soluções eram pensados por poucos, depois da adoção da Qualidade Total todos os problemas são pensados e resolvidos por muitos. Os problemas são assumidos por quem realmente pode resolver.

Com a mudança, descobriu-se que todos sabiam o que precisavam; nas discussões, as idéias foram colecionadas, os problemas identificados, e assim ganharam-se subsídios para o planejamento, que tem por meta satisfazer às necessidades dos clientes.

A Beta tem colocado que realizou "mudanças sem mudar a cultura das pessoas que a constitui, sem mudar a música, as tradiçoes", que mudou "o método e a gestão de trabalho".

Além do discurso da liderança da empresa, foram realizadas entrevistas com o coordenador da Qualidade, a média gerência, operadores e funcionários do "chão de fábrica". Nessas entrevistas, buscou-se identificar as formas de interpretação do processo cognitivo expresso no discurso dos empregados.

Os argumentos utilizados para explicar a implantação do Programa de Qualidade na empresa basearam-se na necessidade de elevação dos padrões de competitividade, embora este dado tenha sido mais utilizado pela média e alta gerências. Os supervisores e os operários enfa-tizaram tarefas e melhoria de relações.

Com relação às mudanças ocorridas após a implantação do Programa, os vários discursos situam a questão em distintos planos cognitivos. Dentre eles, podem ser destacados estes pontos de vista:

diretor industrial: "A necessidade de tornar a empresa competitioa e a descoberta de outros clientes - o acionista, os funcionários, o ambiente onde a empresa está localizada";

coordenador de qualidade: "A tendência é mudar tudo, ainda que a Beta fosse moderna e bem administrada para os moldes brasileiros"; gerente: "A postura das pessoas: ñó é mais aquele lugar que se chegava apenas para o trabalho"; " menos desconfiança e mais confiança dos empregados";

caldeireiro: "Melhor relacionamento com a chefia"; supervisor: "Iá se tem definido o que fazer".

Nas questōes relativas às dificuldades de implantação e desenvolvimento do programa, as respostas são consensuais ao indicarem a resistência das pessoas a mudar "hábitos", "comportamentos" e "rotinas de dez, doze anos"; "começar do zero com o TQC"; "dificuldades de rompimento de rotinas". Para outros, a dificuldade relaciona-se à "reação das pessoas que vêem a qualidade como mais um modismo"; "reações do próprio país, do sindicato, que ainda bate na mesma tecla" e o "aumento da quantidade de trabalho". 


\section{Alfa S.A}

A Alfa S.A produz o linear alquilbenzeno, matéria-prima para detergente biodegradável.

Possui 325 funcionários, número estável há quatro anos, e não contrata atividade terceirizada, exclusive a limpeza e a alimentação. A empresa tem uma capacidade instalada que vem crescendo ano a ano, assim como a sua produção. No ano de 1992 a produção foi de 135 mil toneladas/ano; 25 a $30 \%$ do produto é exportado.

A estrutura da Alfa foi modificada antes de se dar início ao processo de qualidade. As mudanças implicaram demissõcs e a empresa não quis associá-las ao processo de qualidade.

Hoje a estrutura é composta por três diretores, quatro assessores e três gerentes. Ao diretor superintendente estão ligadas as assessorias de mcio ambiente e segurança e outra, de plancjamento estratégico e qualidade. Ao diretor financeiro administrativo estão ligadas as assessorias de orçamento e informática. Com o diretor de novos negócios está a responsabilidade de dirigir as duas fábricas da Alfa, situadas no Rio de Janeiro. Há, ainda, as gerências comercial, de pesquisa e de desenvolvimento industrial. Na gerência industrial está inserida toda a estrutura industrial, manutenção, laboratório, engenharia de processo e operações.

\section{Concepção e gerência do processo de melhoria da qualidade}

A Alfa entende que as mudanças inseridas na empresa devem-se à necessidade de reformulação da sua forma de relacionar-se com fornecedores e clientes.

A empresa apoiou essa mudança no princípio de que o grau de satisfação dos clientes externos e internos traduz, sempre, o compromisso de assegurar a melhoria contínua e qualidade em tudo que fazem. Se os clientes internos não estiverem satisfeitos, os externos também não o estarão.

No entendimento da Alfa, houve resistência ao processo de

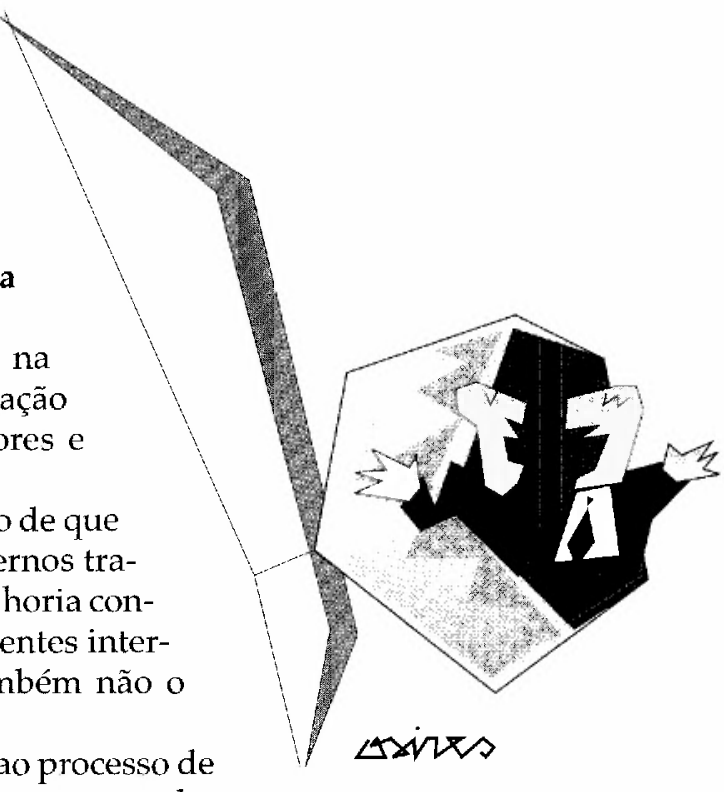
qualidade e buscou-se vencê-las investindo nos recursos humanos, mudando valores e crenças, desde os diretores até o mais simples operário.

A iniciativa de implantar o processo de qualidade partiu de pessoas de nível intermediário na empresa. Foram realizados estudos e apresentada uma proposta à Diretoria, que acreditou na possibilidade. Após a aprovação dessa, a proposta foi encaminhada ao Conselho de Administração para a decisão. Esse Conselho é o órgão que analisa o planejamento, procedendo à sua avaliação a cada seis meses. Hoje considera-se que foram importantes esses compromissos.

A direção da Alfa, ao incorporar a idéia, sugeriu o uso do planejamento estratégico e participativo. Desde então, o planejamento busca envolver todos os recursos humanos da empresa.

A Alfa usa a qualidade no seu planejamento como ferramenta para disputar a competitividade do mercado. Além disso, a ad- 
ministração participativa é considerada elemento forte no processo. O lema é: "Só se amadurece um processo, discutindo com todos, inclusive com a base".

A qualidade é vista não apenas como um produto mas também como qualidade de vida, fator de realização e crescimento das pessoas, para que possam, efetivamente, contribuir para a melhoria contínua da empresa.

Baseada na participação, a Alfa formou um comitê-guia, constituído por sete pessoas, além do diretor superintendente, que lidera todas as áreas da empresa. No Comitê estão representantes de todos os setores. Eles trabalham planejando e estruturando o processo.

Para a Alfa, a política de qualidade envolve, em primeiro lugar, o cliente, buscando corresponder sempre às suas expectativas; em segundo, melhoria contínua; em terceiro, forte processo de educação continuada; em quarto, promoção através do reconhecimento, e, por fim, adequação contínua aos padrões de qualidade.

Para a liderança, o principal investimento da Alfa é em pessoal. Como parte desse investimento foi elaborada uma cartilha para se iniciar o envolvimento das pessoas com os conceitos de qualidade, que precisavam ser compreendidos por todos os trabalhadores. No entanto, essa cartilha só foi elaborada depois do sistema aprovado e em implantação.

A Alfa realizou todo o processo sem consultoria externa. Partiram do pressuposto de que nem todas as pessoas precisam saber tudo, muito menos ao mesmo tempo; assim, o programa de treinamento foi feito por módulos. Dividido em partes, o curso só vai adiante quando é preciso e quando os treinandos têm condições de avançar. É dividido e adaptado, feito com o perfil da empresa. As pessoas aprendem o que precisam, avançam devagar no processo.

O processo da Alfa foi dividido em duas partes: uma frente faz a qualidade total até a ISO 9000 e a outra, além da ISO 9000, persegue a qualidade total, buscando a ISO 9002.

A ISO 9004 está sendo perseguida de acordo com a evolução do processo. Acredita-se que todo o sistema estará implementado até dezembro de 1994.

O modelo normativo da empresa é a ISO 9002. "Diga o que faz, pratique o que diz e mostre o que faz, com evidência, com aferição, com controle de qualidade."

A estrutura do método utilizado engloba procedimentos que se subdividem em instruções operacionais, métodos analíticos (laboratórios) e especificações entre correntes de processos e produtos finais.

AAlfa, após a montagem do sistema, dos procedimentos e dos cronogramas de implantação, escolheu dez auditores do próprio quadro da empresa, para verificar a implantação e adequação do processo às normas.

Realizaram o chamado Mutirão da Inconformidade e, durante três meses, todo o pessoal da Alfa esteve envolvido em consertar aquilo que não estava dentro dos padrões exigidos.

Após o mutirão, contrataram uma empresa para realizar a préauditoria e, finalmente, outra, para proceder à certificação. Nas 
palavras da liderança da empresa "a certificação aumentou o 'astral' da empresa. O aprimoramento do sistema envolveu os fornecedores, que criaram a confiabilidade metrológica que a ISO 9000 pede".

\section{Repercussões do processo e impacto na cultura da organização}

$\mathrm{Na}$ Alfa, os empregados organizam grupos de estudos que, continuamente, viabilizam a implementação do processo. Os grupos são interdisciplinares e os estudos são variados. Eles influem no processo e, na sua opinião, isso tem trazido resultados, inclusive financeiros.

Um desses estudos gerou a campanha contra o desperdício, que atua, inclusive, no refeitório, controlando diariamente, através de mural, os alimentos desperdiçados.

A empresa descobriu, também, que a melhor metodologia é desenvolver um modelo próprio que envolva todas as pessoas. E reiteram: "As vantagens de se desenvolver um modelo próprio é que este, embora demore para ser elaborado, rapidamente é implantado e não tem recaida. Tem uma consolidação efetiva e garantida; tem aderência porque o que diz que faz, faz mesmo; exige maior profundidade; menores custos; mudança comportamental e pró-ativa. Integra todas as áreas e permite a visão do todo".

O lema da empresa é: "Somos 325 que valem 9002".

A Alfa mudou a forma de avaliar o desempenho, e o entende sem vinculação com lucros, mas sim com performance.

Houve ainda uma mudança na forma de o empregado relacionar-se com a empresa. "Ele está preocupado com o que faz, porque é responsável com a solução de problemas."

Várias açōes foram implementadas, buscando "quebrar o gelo" e favorecer a integração. A exemplo disso, a campanha da limpeza foi feita através de performance teatral. Os empregados também estão organizados em teatro e coral.

A participação nos lucros é uma ação que já existe há onze anos na Alfa. A mudança que ocorreu após a qualidade total é que os empregados participam mais dos lucros à medida que a empresa melhora o seu desempenho.

Nas entrevistas realizadas na Alfa, com seus empregados, com gerentes, coordenadores de áreas e operadores, foram reveladas formas de interpretações do processo de qualidade por vezes semelhantes em determinados aspectos, mas, também, com algumas diferenciações no nível das significações individuais.

O maior consenso localiza-se nas interpretações pessoais acerca das motivações da empresa ao adotar o processo de qualidade. Há uma unanimidade de opiniões na resposta à questão: por que a Alfa implantou o Programa de Qualidade?

As respostas, via de regra, referiam-se à necessidade da empresa de "utilizar o mercado externo"; "colocar o nosso produto no exterior"; "qualidade voltada ao mercado internacional"; "ganhar competitividade"; "necessidade de sobrevivência da empresa"; "necessidade de conseguir o certificado ISO 9000".

Quando a questão se referia às mudanças ocorridas na empresa após a implantação do processo, as respostas continham interpretações diferenciadas, em alguns casos em função do cargo ocupado. Eis algumas das respostas: 
- coordenador da área mecânica e engenharia: "A qualidade formalizou processos e procedimentos que estavam na cabeça das pessoas e não no papel, mudanças do informal para o formal".

- mecânico: "O processo não mudou muita coisa, a equipe tomou consciência de que já faziamos um trabalho de qualidade"; "agora vemos cada um de nós como cliente e fornecedor".

" operador: "Diminuiu a distância entre chefia e subordinado"; "os chefes diminuiram as barreiras"; "a moral e a satisfação subiram".

Quanto à questão sobre as dificuldades de implantação do processo, as respostas revelaram diferentes interpretações em função dos cargos ocupados. Os entrevistados que ocupavam postos de "chão de fábrica" foram unânimes ao expressarem a ausência de dificuldades no processo. Ao contrário, a gerência média unanimemente afirmou que a maior das dificuldades na implantação do processo se devia à "resistência das pessoas à mudança", ainda que "as pessoas não precisassem ser substituídas", e referiu-se ainda à "dificuldade de conscientizar as pessoas que acham que não precisam mudar porque o que fazem já é bom" e que "as pessoas geralmente têm tendência a se acomodar".

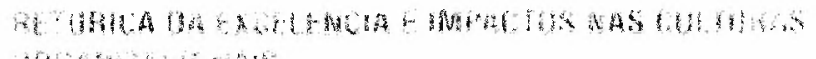

Thas

A expressão, a fala, o discurso, a retórica, enfim, manifestam uma interpretação cognitiva de experiências, do mundo cotidiano e dos processos interativos.

O discurso, em situações da necessária interação entre competência e comportamento, como as que tivemos acesso na pesquisa, examinamolo não apenas de modo a descobrir o caráter normativo, mas o cotidiano, a significação pessoal que se ressalta apesar das "regras".

E mesmo as regras, presentes na fala e discurso, adaptam-se a situações particulares. Normas e regras têm, para todos, interpretações pessoais.

Desse modo, as interpretações pessoais colhidas na pesquisa exprimem por vezes formas diferenciadas de significações em relação aos processos de qualidade nas duas empresas. As permanências e o potencial de inovação são-lhes, portanto, devidos.

Um ponto muito marcante nos discursos relaciona-se aos problemas ligados à resistência à mudança - expresso apenas nas falas da alta $\mathrm{e}$ média gerências. Para estas, o processo de qualidade "mudou tudo", e os funcionários resistem às mudanças, ou por insegurança quanto ao novo, ou por acreditar que o que eles fazem já tem qualidade.

No entanto, para esses funcionários ("chão de fábrica") o que mudou de fato foi a qualidade do relacionamento com a chefia, em primeiro lugar. Os processos de trabalho, para alguns, não mudaram, porque já eram de qualidade e o que houve foi o reconhecimento dessa qualidade anterior pela empresa.

Quanto a uma interpretação dos motivos que levaram as empresas a adotarem processos e programas de qualidade, apenas a alta e média gerências recorrem a explicações relativas a estratégias de mercado, baseadas na necessidade de se elevarem os níveis de produtividade e competitividade como garantia de sobrevivência. Para o "chão de fá- 
brica", os objetivos interpretados restringem-se, em muitos casos, à obtenção da certificação do produto. Enquanto, para alguns, o processo de qualidade "não mudou nada", para outros, mudou a sua própria forma de relacionamento com o mundo cotidiano, mudou a própria vida.

Contradições e paradoxos são vividos entre as injunções da retórica da excelência e as pautas de comportamento baseadas em valores permanentes da organização.

A retórica da excelência sinaliza, contraditoriamente, para ruptura com o passado e consenso no presente.

$O$ "discurso oficial" e a organização vivida têm alguns sérios paradoxos. Um deles é a convivência de padrões de competição e cooperação. Nunca se competiu tanto e nunca houve tanta valorização da cooperação no plano do discurso no sentido de se construir uma "cultura vitoriosa".

Ao insistir nesses aspectos, entendemos que este universo de significações, de crenças e valores exprime graus de interatividade, compreensão e comprometimento com os processos de mudança e, no plano da cultura organizacional, promove ou inibe o potencial de contribuição, de criatividade e de inovação na organização.

É imperativo, portanto, entrar nesse universo de formas, de significações e de condutas simbólicas, que um indivíduo ora conhece e dirige, ora percebe intuitivamente e deixa como está, ora ignora e suporta.

E, finalmente, chama-se a atenção para a necessária congruência entre o pensar, o falar e o agir na retórica da excelência. Quanto mais significado tiverem os conceitos, mais possibilidades existem de que sejam apreendidos e vividos na construção do paradigma cultura.

\section{BIBLIOGRAFIA SUPLEMENTAR}

ALDRICH, Howard E. Incommensurable paradigms? Vital Signs from Three Perspectives. In: REED, Michael, HUGHES Michael (eds.). Rethinking organizations: new directions in organization theory and analysis. London: Sage Publications, 1992

ALLAIRE, Y. Cultures Organisationalles. Québec: Gaaten Morin, 1988.

BELTRAN, A. G, RUFFAUT, M. Culture d'entreprise et histoire. Paris: Les Éditions d'Organisation, 1991.

CAILLIES, A. Japan: confrontetion culturelle dans l'entroprise mixte. Paris: Méridiens, 1986.

CICOUREL, A. Cognitive sociology. Londres: Penguim Books, 1973.

CHANLAT, J. F. L'individu dans l'organisation. Québec: Éditions Eska, 1991.

DEAL, Terrence, KENNEDY, Alan. Corporate culture the rites and rituals of corporate life. Massachusets: AddisonWesley, 1982.

DEMING, W. E. Elementary principles of the statistical control of quality. Tóquio: Nippon Kagaku Gijutsu Remmei, 1951.

FROST, P. et al. Refraiming organizational culture. Londres: Sage, 1991.

HOFSTEDE G. Cultural consequences; intemational differences in work-rslated values. Beverly-Hills: Sage, 1980; Measuring organizational culture; a qualitative anal quantitative study across twenty cases. Administrative Sclence Quarterly, v. 35, n.2, 1990

IRIBARNE,P. Cultures nationales et gestion: ce qui est universal et ce qui ne l'est pas. Revue Française de Gestion, v. 64, n.4, Paris, 1987.

MACHADO DA SILVA, C; FONSECA, V. Estruturaçăo da estrutura organizacional: o caso da uma empresa familiar. Organizaçōes e Sociedade. Salvador: UFBA, 1993

MARTIN, J. Cultures in organizations. NewYork: Oxford University Press, 1991.

MASLOW, A. H. Motivation and personality. New York: Harper and Bros. 1954.

RAELIN, J. Clash of cultures. Managers and professionals. Boston: Harvard Businesss School Press, 1986.

SACKMANN, S. Cultural knowledge in organizations. Londres: Sage, 1991.

SAINSALIEU, R. L'identité au travail. Paris: Presse de la Foundation Nationale des Sciences Politiques, 1987.

TELBOUKL, J. Gerenciando a dinâmica da qualidade. Rio de Janeiro: Qualitymark, 1991 . $\square$

\section{7}

Artigo recebido pela Redação da $R A E$ em agosto/94, avaliado e aprovado para publicação em novembro/94. 